\title{
Further Observations on Conditioned Pyridoxin Deficiency in Rats during Lactation
}

\author{
BY MARION B. RICHARDS \\ Rowett Research Institute, Bucksburn, Aberdeenshire
}

(Received 30 August 1948)

The preceding paper (Richards, 1949) described the effect of diets containing flours of different extraction rates on the conditioned pyridoxin deficiency caused by excessively high intake of vitamin $B_{1}$, results being given for four generations of rats. The does of the first generation, after completing three lactations in their original groups, were used for various experiments designed to gain further information on the question of pyridoxin deficiency during lactation, and its effect on the weight of the thymus glands of the weanling rats. These experiments included: ( 1 ) transference of does from one group to another; (2) interchange of sucklings among different groups; (3) oral administration of pyridoxin to part of a litter during suckling.

Nearly $25 \%$ of the does failed in the fourth mating, either when kept in their original group or when transferred to another group. A few of these had been erratic in their breeding performances in the earlier tests, but a number of the fourth-mating failures occurred in does which had had an excellent breeding record for the first three litters. Since none of the failures occurred in does of the original group which throughout received a daily supplement of $40 \mu \mathrm{g}$. pyridoxin added to $72 \%$ extraction flour, and since some failures were recorded in each of the other groups, it seems probable that this early falling off in reproduction was partly due to the prolonged ingestion of the unbalanced diets.

\section{METHODS}

The experimental methods were similar to those employed in the previous paper (Richards, 1949).

\section{RESULTS}

Transference of does from one group to another

Transference of does from $72 \%$ extraction flour to the pyridoxin group ( $72 \%$ extraction flour plus pyridoxin) or to $85 \%$ extraction flour

Of four does transferred from the $72 \%$ extraction flour group to the pyridoxin group one was discarded 46 days after mating, as there was no sign of pregnancy. The breeding records for the other three does, and for two does transferred to the $85 \%$ extraction flour group, are given in Table I (Exps. I-5). It will be seen that although fits had been numerous in the litters of the does when on the $72 \%$ extraction flour diet, no fits occurred in the litters born after the transference to either of the other diets. In all the litters except one there was a marked increase in the weaning weights after the transference. The litter which showed a decrease included five adopted rats which 
were only 21 days old when weaned. Changing the diet of the does had a very marked effect on the thymus weight of the weanlings. Averages of 202, 247, 209, 167 and $253 \mathrm{mg} . / 100 \mathrm{~g}$. body-weight for the three litters of each of the five does on $72 \%$

Table I. Effect on incidence of fits, on weaning weights and on thymus gland weights of the offspring of changing the percentage extraction of the flour in the diet of does after three matings in original groups, as described in the preceding paper (Richards, 1949)

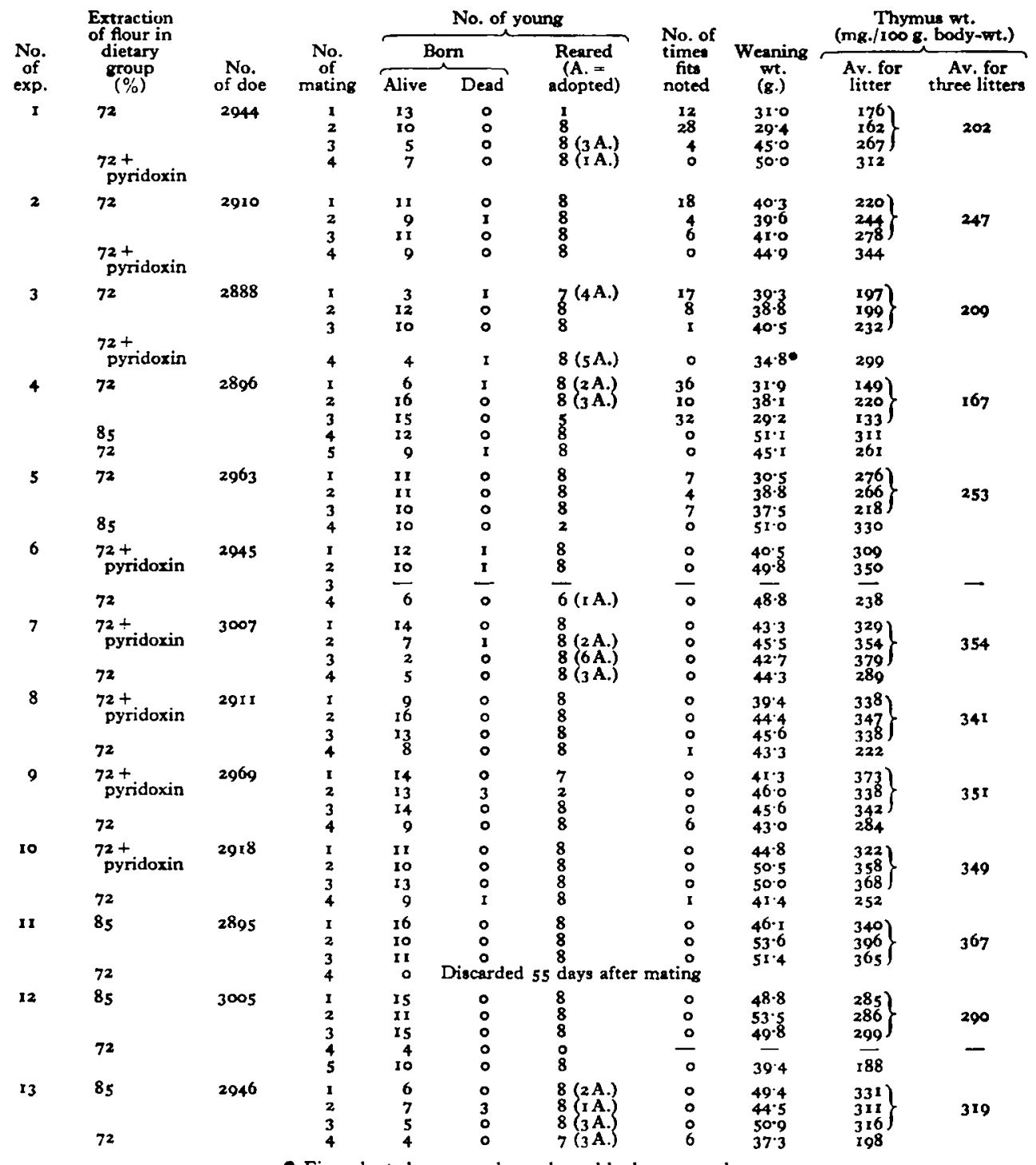

- Five adopted young only 21 days old when weaned.

extraction flour were increased to $312,344,299,31 \mathrm{I}$ and $330 \mathrm{mg}$., respectively, when the diet included pyridoxin or $85 \%$ extraction flour.

Doe 2896 , which was restored to the $72 \%$ extraction flour diet for a fifth mating, 
gave a much better performance than with the three earlier litters on this diet. This might be due partly to the tendency to improvement previously noted (Richards, 1949) with increasing maturity of the doe in successive lactations, but it seems probable that the beneficial results, in part at least, represent an after-effect from the period on the higher extraction flour. There was some falling off in the thymus and weaning weights compared with the values on the $85 \%$ extraction flour diet, but they were still considerably greater than those obtained in the earlier litters. Also, no fits were observed in the sucklings, although fits had been very numerous even in the third mating when many of the does in the group had shown an improvement.

\section{Transference of does from the pyridoxin group ( $72 \%$ extraction flour plus pyridoxin) to the group on $72 \%$ extraction flour diet}

Of five does which had received $72 \%$ extraction flour plus pyridoxin from weaning, all reared litters when the pyridoxin was withdrawn (Table r, Exps. 6-ro). The beneficial effects of the prolonged administration of pyridoxin were very evident from the records of the incidence of fits, the thymus weights and the weaning weights. Two of the litters showed no fits at all, two showed one fit each, and in the remaining litter only six fits were noted. This lessened susceptibility to fits in the litters of does given pyridoxin until they were fully grown is in accordance with a previous finding (Richards, 1949) that stock adults when fed on diets of high vitamin $B_{1}$ content were less susceptible to the induced pyridoxin deficiency than does reared from weaning on the unbalanced diets. The after-effect of pyridoxin administration was seen also in the thymus weights of the weanlings. In all cases the thymus weights were reduced when pyridoxin was withdrawn, but not generally to the level found when the does had throughout received the $72 \%$ extraction flour diet, although two litters gave low values of 222 and $238 \mathrm{mg}$. I roo g. body-weight. Another thymus value $(252 \mathrm{mg} / 100 \mathrm{~g}$.) was definitely below normal (300-400 mg./100 g.), but two of the values found (284 and $289 \mathrm{mg} . / 100 \mathrm{~g}$.), though considerably below those found in the litters of the same does when they received pyridoxin, were not far below the lower limit of what may be considered normal. Weaning weights were not consistently affected by the withdrawal of pyridoxin, but they were considerably higher than the average weights of litters of does kept throughout on the $72 \%$ extraction flour diet.

\section{Transference of does from $85 \%$ extraction flour diet to $72 \%$ extraction flour diet}

There was less evidence of an after-effect with this change than in the animals transferred from the pyridoxin group to the $72 \%$ extraction flour diet (Table $\mathrm{r}$, Exps. I I-13). Doe 2895, which had been an excellent breeder in the three matings on the $85 \%$ extraction flour diet, failed to produce a litter on the $72 \%$ extraction flour diet. Doe 3005 failed to rear her first litter after transference but succeeded in a second attempt. These failures, however, cannot justly be ascribed to the change of diet, since two other does which were continued on the $85 \%$ extraction flour diet failed also at the fourth mating. The incidence of fits seemed to give some evidence of an after-effect from the previous diet. The litter reared by doe 3005 showed no fits, and that reared by doe 2946 showed fits only six times. Thymus and weaning weights were much reduced 
in the litters on the $72 \%$ extraction flour diet, and gave no suggestion of any aftereffect. Thus, for doe 3005 an average weaning weight of $50.7 \mathrm{~g}$. and a thymus weight of $290 \mathrm{mg}$. $/ \mathrm{ro0} \mathrm{g}$. body-weight for three litters on $85 \%$ extraction flour became $39.4 \mathrm{~g}$. and $188 \mathrm{mg} . / 100 \mathrm{~g}$. respectively, on $72 \%$ extraction flour. For doe 2946 the corresponding values of $48.3 \mathrm{~g} . / 100 \mathrm{~g}$. and $319 \mathrm{mg} / \mathrm{r} 00 \mathrm{~g}$. were reduced to $37.3 \mathrm{~g}$. and $198 \mathrm{mg} / \mathrm{ro0} \mathrm{g}$.

Thus, transference of does from 72 to $85 \%$ extraction flour or to $72 \%$ extraction flour plus pyridoxin prevented the occurrence of fits in the sucklings and caused a marked increase in their weaning weights and thymus weights. The opposite effects were in general obtained, though they were less marked, when the reverse transferences were made. Animals that had received less unbalanced diets from weaning to adult age seemed to be more resistant to the induced pyridoxin deficiency when transferred to the $72 \%$ extraction flour diet. This was particularly noticeable in the does which had received pyridoxin from weaning until they had completed three lactations. When pyridoxin was withdrawn from these does their litters had fewer fits, and the reduction in thymus weight of the weanlings was less marked, than in the litters of does reared throughout on the $72 \%$ extraction flour diet.

\section{Interchange of sucklings among different groups}

A study of the weaning weights and thymus weights of young rats suckled by a foster-mother shows that in conditioned pyridoxin deficiency the milk of the does is lacking in quality rather than in quantity. Material for this study was obtained from the fourth mating of the first generation rats used in the flour experiments (Richards, I949). Sucklings from the group receiving $85 \%$ extraction flour were exchanged with sucklings from the group receiving $72 \%$ extraction flour, the number of does in the latter group being augmented with does which had received 77 or $80 \%$ flour for their earlier matings. Further material was obtained by various adoptions made throughout the experiments in attempting to equalize the size of the litters reared. As before (Richards, 1949), whenever possible a doe was given eight young to suckle, larger litters being reduced to eight 2 days after birth, and smaller litters being brought up to eight if suitable young were available for adoption. If surplus young from the same group were not available, young from other groups were taken, and these supplied some of the material for the present study. The effects on weaning weight and thymus weight of these interchanges and adoptions are shown diagrammatically in Fig. $\mathrm{r}$.

(a) Does 2903 and 2975. In the exchange of sucklings between these does weaning weights were scarcely affected, but thymus weights showed considerable variation. Thus, of four males born to doe 2903 , having $85 \%$ extraction flour, two reared by herself had a weaning weight of $53.0 \mathrm{~g}$. and a thymus weight of $302 \mathrm{mg} / 100 \mathrm{~g}$. bodyweight, whereas two reared by doe 2975 having $72 \%$ extraction flour had a weaning weight of $5 \mathrm{I} \cdot 0 \mathrm{~g}$. and a thymus weight of only $236 \mathrm{mg} / / \mathrm{ro0}$. Similarly, of four males born to doe 2975 having $72 \%$ extraction flour, two reared by herself had a weaning weight of $49.5 \mathrm{~g}$. and a thymus weight of $270 \mathrm{mg} . / 100 \mathrm{~g}$., whereas two reared by doe 2903 on $85 \%$ extraction flour had the same weaning weight but a thymus weight 

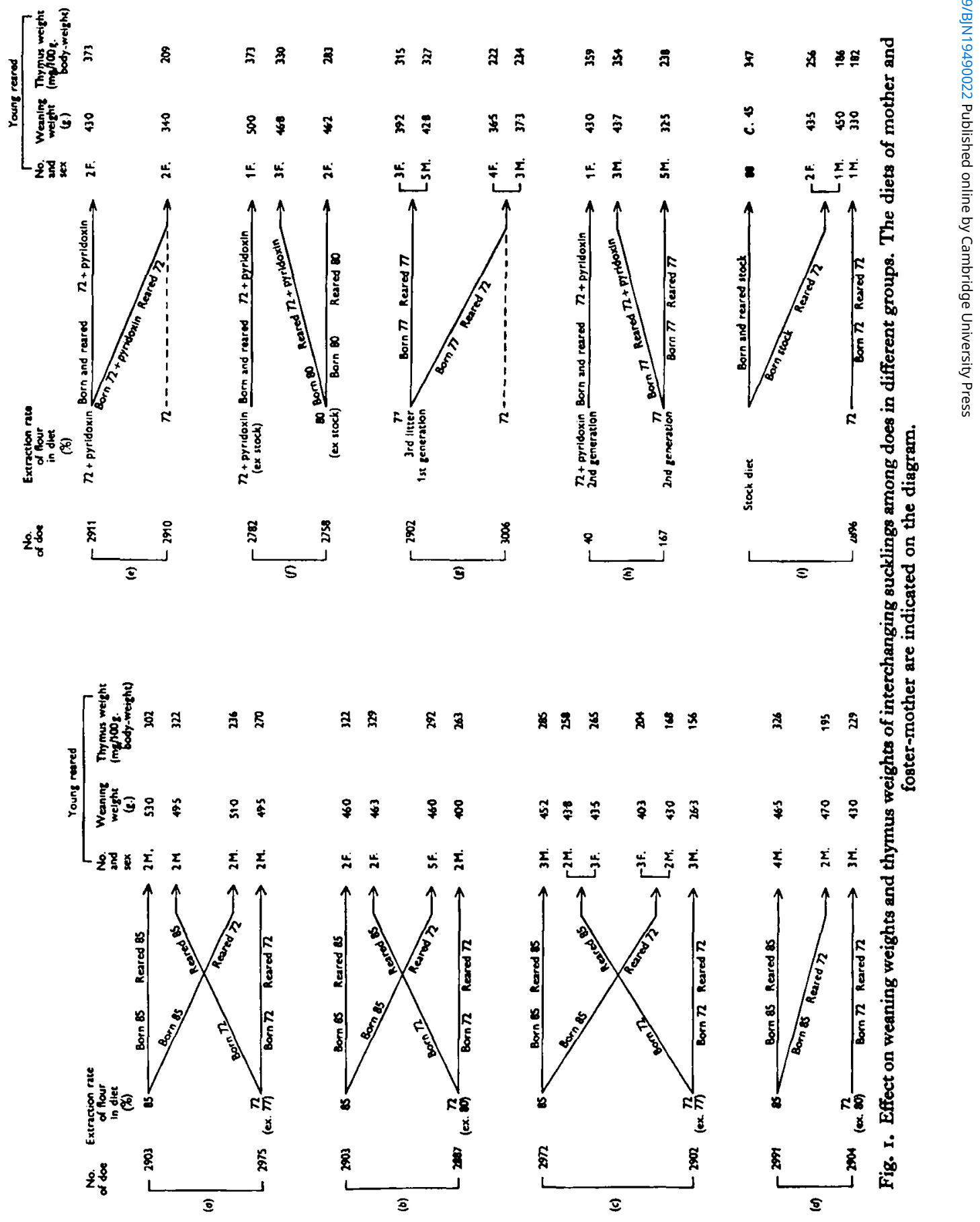
of $322 \mathrm{mg}$./ $100 \mathrm{~g}$. The similarity of the weaning weights indicates that there was no deficiency in quantity of the doe's milk on the $72 \%$ extraction flour diet, but a deficiency in quality is indicated by the lower thymus values.

(b) Does 2903 and 2887. Three sets of female sucklings involved in this interchange all had the same weaning weight of $46 \mathrm{~g}$, , but the thymus weights were 322 and $329 \mathrm{mg} . / 100 \mathrm{~g}$. body-weight on the $85 \%$ extraction flour diet and $292 \mathrm{mg} . / 100 \mathrm{~g}$. on the $72 \%$ extraction flour diet.

(c) Does 2972 and 2902. In this pair the differences in thymus weight on the two diets were very marked. Of five males born to doe 2972 having $85 \%$ extraction flour, three reared by herself had a weaning weight of $45.2 \mathrm{~g}$. and a thymus weight of $285 \mathrm{mg}$./ I00 g. body-weight, whereas two suckled by doe 2902 having $72 \%$ extraction flour had a weaning weight of $43.0 \mathrm{~g}$. but a thymus weight of only $168 \mathrm{mg} . / 100 \mathrm{~g}$. Of five males born to doe 2902, two reared by doe 2972 on the $85 \%$ extraction flour diet had a weaning weight of $43.8 \mathrm{~g}$. and a thymus weight of $258 \mathrm{mg}$. $/ 100 \mathrm{~g}$. body-weight, whereas those reared by their own mother on the $72 \%$ extraction flour diet had a thymus weight of $156 \mathrm{mg}$./100 g. In this case the weaning weight also was very low $(26.3 \mathrm{~g}$.). This low weight suggests poor quality in the young rats born to doe 2902 , since the adopted pair born on $85 \%$ extraction flour diet and reared by doe 2902 , reached a weight of $43.0 \mathrm{~g}$. The pair born to doe 2902 and reared by doe 2972 showed much better weaning and thymus weights than those reared by doe 2902 herself, but both weights were below those attained by doe 2972's own young.

(d) Does 299r and 2904. This transference from 85 to $72 \%$ extraction flour diet was followed by no drop in weaning weight, but thymus weights fell from 326 to $195 \mathrm{mg}$./ $100 \mathrm{~g}$. body-weight.

(e) Does 29ri and 29ro. When young were transferred from doe $29 \mathrm{II}$ in the pyridoxin group to her litter-mate 2910 in the $72 \%$ extraction flour group, there was a very marked drop in thymus weights from 373 to $209 \mathrm{mg}$./100 g. body-weight and also a marked drop in weaning weight from 43 to $34 \mathrm{~g}$.

$(f)$ Does 2782 and $275^{8}$. These were two of the adult stock does which proved in general less susceptible to the conditioned pyridoxin deficiency than rats reared from weaning on the unbalanced diets. Even in this case, however, transference of young from the $80 \%$ extraction flour diet to the pyridoxin group increased thymus weight considerably, the weaning weight being unaffected, but both weaning and thymus weights of the adopted young were below those attained by a rat born and suckled in the pyridoxin group. The data thus indicate better quality both of the milk and of the young in the group receiving $72 \%$ extraction flour supplemented by pyridoxin than in the group receiving $80 \%$ extraction flour.

(g) Does 2902 and 3006 . Doe 3006, receiving $72 \%$ extraction flour, had only one young one born alive, but she reared seven adopted from doe 2902, receiving $77 \%$ extraction flour, which had produced a litter of seventeen young at the third mating. The thymus weights of the adopted young, however, were only $222-234 \mathrm{mg}$. $/ 100 \mathrm{~g}$. body-weight, whereas those of the young suckled by doe 2902 were $315-327 \mathrm{mg}$./100 g.

(h) Does 40 and 167 (second generation). Both the pyridoxin and $77 \%$ extraction flour groups showed, in general, considerable deterioration in the second-generation 
breeding tests, but the superiority of the pyridoxin group was made evident by the result of transferring to this group three males from doe 167 receiving the $77 \%$ extraction flour diet. The weaning weight increased from 32.5 to $43.7 \mathrm{~g}$. and the thymus weight from 238 to $354 \mathrm{mg}$./100 g. body-weight.

(i) Doe 2896. Doe 2896 on the $72 \%$ extraction flour diet suckled one male and two female young ones from a stock doe. The weaning weights of the adopted young, which were approximately normal, taken in conjunction with the lowered thymus weights, indicate again that quality rather than quantity was deficient in the milk of the doe on the $72 \%$ extraction flour diet, and the low weaning weight of a young one born to doe 2896 is indicative of inferior quality in this suckling, arising from the nutritional defects to which the doe had been subjected.

Consideration of these data makes it clear that there was in the milk of does suffering from conditioned pyridoxin deficiency a definite deficiency in quality, as evidenced by the subnormal weight of the thymus glands of the weanlings. The weight deficit of the thymus could be lessened or made good by transferring the sucklings soon after birth to a doe receiving the $85 \%$ extraction flour diet or to one receiving pyridoxin. The effect on the thymus seemed to be very largely the result of this deficiency in lactation, but there were indications also of the influence of inferior quality in the offspring of does suffering from the conditioned pyridoxin deficiency.

\section{Oral administration of pyridoxin to sucklings}

In this experiment $20 \mu \mathrm{g}$. of pyridoxin were administered daily by mouth to part of a litter during the suckling period to test whether any qualitative defect in the milk could be thus made good, the quantity of milk available being presumed to be the same for all members of the litter. The test was made on the litters of does having the 72 , 77 and $80 \%$ extraction flour diets, some of the does in the $72 \%$ group having been previously in the 77 or $80 \%$ group. The results, given in Table 2 , varied considerably in different litters. In some instances both the weaning weight and the thymus weight were higher in the young given pyridoxin; in some the thymus weight was higher without any increase in the weaning weight, or the opposite occurred, and in some cases there was little effect. The technique of the experiment, however, was not beyond criticism. The dosing of the young rats was begun at $3-7$ days of age, and it was unavoidable that the doe should receive a certain amount of pyridoxin from licking the face of the suckling and possibly also from the excreta. This would tend to increase the pyridoxin content of the milk, from which all the young would derive benefit. As the sucklings grew older, moreover, those not receiving pyridoxin would be able to obtain some of the vitamin directly by licking the dosed animals. There was thus no clear-cut separation between dosed and undosed young, and it may be significant that no fits were observed in the litters on the $72 \%$ extraction flour diet among the young rats not dosed with pyridoxin. In spite of the technical difficulties, the bulk of the evidence indicates that direct administration of pyridoxin to the sucklings did have a favourable effect.

Litter of doe 2967. In this litter administration of pyridoxin had a marked effect on 
both weaning and thymus weights. In the males the weaning weight increased from 40.0 to $46.8 \mathrm{~g}$., and the thymus weight from $\mathrm{r} 84$ to $320 \mathrm{mg}$./ $/ \mathrm{ro0} \mathrm{g}$. body-weight. In the females the weaning weight increased from 40.3 to $45^{\circ} \circ \mathrm{g}$., and the thymus weight from 268 to $311 \mathrm{mg}$./100 g. body-weight.

Table 2. The effect on weaning weight and thymus gland weight of oral administration of pyridoxin to sucklings of does receiving a diet high in vitamin $B_{1}$ and containing flours of varying degrees of extraction which induced a conditioned pyridoxin deficiency of graded severity

\begin{tabular}{|c|c|c|c|c|c|c|c|}
\hline \multirow[b]{2}{*}{$\begin{array}{l}\text { No. of } \\
\text { doe }\end{array}$} & \multirow[b]{2}{*}{$\begin{array}{l}\text { Extraction } \\
\text { rate of flour } \\
\text { in diet } \\
(\%)\end{array}$} & \multicolumn{3}{|c|}{ Without pyridoxin } & \multicolumn{3}{|c|}{ With pyridoxin } \\
\hline & & $\begin{array}{l}\text { Weaning } \\
\text { wt. } \\
\text { (g.) }\end{array}$ & $\begin{array}{l}\text { No. of } \\
\text { animals }\end{array}$ & $\begin{array}{c}\text { Thymus } \\
\text { wt. } \\
\text { (mg./100 g. } \\
\text { body-wt.) }\end{array}$ & $\begin{array}{l}\text { Weaning } \\
\text { wt. } \\
\text { (g.) }\end{array}$ & $\begin{array}{l}\text { No. of } \\
\text { animals }\end{array}$ & $\begin{array}{c}\text { Thymus } \\
\text { wt. } \\
\text { (mg./100 g. } \\
\text { body-wt.) }\end{array}$ \\
\hline \multicolumn{8}{|c|}{ Male weanlings } \\
\hline 2967 & $72(72)$ & 40.0 & 2 & 184 & $46 \cdot 8$ & 2 & 320 \\
\hline 2910 & $72(72)$ & 63.5 & I & 280 & - & - & - \\
\hline 2919 & $72(77)$ & 47.0 & 2 & $23^{8}$ & $46 \cdot 5$ & 2 & 316 \\
\hline 2968 & $77(77)$ & $49 \cdot 0$ & $I$ & 208 & 53.5 & I & 329 \\
\hline 2984 & $72(80)$ & - & 一 & - & - & - & - \\
\hline 2905 & $72(77)$ & $48 \cdot 3$ & 2 & 233 & 53.5 & 2 & 267 \\
\hline 2894 & $72(80)$ & $41 \cdot 0$ & I & 296 & $44^{\circ} \circ$ & 2 & 299 \\
\hline 2943 & $80(80)$ & $5^{8 \cdot 8}$ & 2 & 229 & $50 \cdot 3$ & 2 & 261 \\
\hline 2971 & $80(80)$ & $56 \cdot 0$ & $I$ & 324 & 55.5 & 2 & 353 \\
\hline \multicolumn{8}{|c|}{ Female weanlings } \\
\hline 2967 & $72(72)$ & $40 \cdot 3$ & 2 & 268 & $45^{\circ} 0$ & 2 & 3 II \\
\hline 2910 & $72(72)$ & - & - & - & $61 \cdot 0$ & I & 400 \\
\hline 2919 & $72(77)$ & 43.5 & 2 & 235 & $47 \cdot 5$ & 2 & 378 \\
\hline 2968 & $77(77)$ & $48 \cdot 2$ & 3 & 282 & $48 \cdot 9$ & 3 & 323 \\
\hline 2984 & $72(80)$ & $51 \cdot 0$ & 1 & 311 & $58 \cdot 0$ & I & 350 \\
\hline 2905 & $72(77)$ & $45 \cdot 3$ & 2 & 279 & $51 \cdot 0$ & 2 & 280 \\
\hline 2894 & $72(80)$ & $43^{\circ} 0$ & 3 & 334 & $38 \cdot 5$ & 2 & 317 \\
\hline 2943 & $80(80)$ & 53.0 & I & 289 & 53.0 & $\mathbf{I}$ & 254 \\
\hline 2971 & $80(80)$ & $53 \cdot 5$ & 2 & 392 & $55 \cdot 5$ & 2 & 398 \\
\hline
\end{tabular}

- The figures in parentheses give the extraction rate of the flour in the diet in the earlier matings

Litter of doe 2910. The thymus weight for a female weanling receiving pyridoxin was 400 , that of an undosed male was $280 \mathrm{mg}$./100 g. body-weight.

Litter of doe 2919. The male weanlings showed no increase in weight with pyridoxin dosing, but the thymus weight increased from 238 to $316 \mathrm{mg}$./100 g. body-weight. The thymus weights of the females increased still more, from 235 to $378 \mathrm{mg}$./100 g. bodyweight, and there was also a body-weight increase of $4 \mathrm{~g}$.

Litter of doe 2968. The thymus weight increased markedly from 208 to $329 \mathrm{mg} .1$ $100 \mathrm{~g}$. body-weight in the male given pyridoxin, accompanied by an increase of $4.5 \mathrm{~g}$. in weaning weight. The thymus weight of the females increased from 282 to $323 \mathrm{mg}$./100 g., but the weaning weight was scarcely affected.

Litter of doe 2984. A female weanling without pyridoxin weighed $5 \mathrm{r} \cdot \mathrm{Og}$., and had a thymus weight of $31 \mathrm{I} \mathrm{mg}$./100 g. body-weight; one with pyridoxin weighed $7 \mathrm{~g}$. more, and had a thymus weight of $350 \mathrm{mg} . / 100 \mathrm{~g}$.

Litter of doe 2905. Both male and female young increased considerably in weaning 
weight with pyridoxin dosing, but the thymus of the females was unaffected, and the thymus weight of the males increased only from 233 to $267 \mathrm{mg}$./100 g. body-weight.

In the three remaining litters changes were mostly small, and there were one or two instances of decrease in weaning weight or thymus weight in the pyridoxin-fed animals, but in spite of such discrepancies the results bear out the interpretation that the milk of the doe on these unbalanced diets was deficient in pyridoxin, and that this deficiency was the cause of the low weight of the thymus glands of the weanlings.

\section{SUMMARY}

x. When does were transferred after three lactations from a diet high in vitamin $B_{1}$ and containing $72 \%$ extraction flour which caused a conditioned pyridoxin deficiency (Richards, I949), to the same diet containing $85 \%$ extraction flour, no fits occurred in the litters and there was a marked increase in body-weight and in the weight of the thymus glands of the weanlings.

2. A similar effect was produced when the does were continued on the diet containing $72 \%$ extraction flour, but were given a daily supplement of $40 \mu \mathrm{g}$. pyridoxin. The beneficial effect of the $85 \%$ extraction flour must, therefore, have been due largely to its pyridoxin content.

3. When pyridoxin was withheld from does after three lactations on the diet containing this vitamin, the animals proved less susceptible to the conditioned pyridoxin deficiency than those reared from weaning on the $72 \%$ extraction flour diet. Fits occurred in the litters, but with diminished frequency and intensity, and thymus weights were reduced, but not usually to the very low level generally associated with this diet. Animals given the $85 \%$ extraction flour diet until fully adult seemed also to be somewhat less susceptible to fits when transferred to the $72 \%$ extraction flour diet, but thymus weights were definitely low.

4. Thymus weights of young born on the $85 \%$ extraction flour diet or on the diet with pyridoxin were diminished when the sucklings were reared by a foster-mother on the $72 \%$ extraction flour diet and, conversely, young born on the $72 \%$ extraction flour diet had thymus glands approaching the normal in weight when reared by a doe on the $85 \%$ extraction flour diet or by one receiving pyridoxin.

5. A beneficial effect on weaning weight and thymus weight was obtained in some cases by administering pyridoxin directly to part of a litter during the suckling period.

6. Although there were some indications of inferior quality in the young born on the unbalanced diets, it is concluded from these studies that the diet of the doe during lactation was the prime factor in determining the weight of the thymus glands of the weanlings, that atrophy of the thymus when it occurred was due to qualitative rather than quantitative deficiency in the doe's milk, and that the deficiency was definitely one of pyridoxin.

\section{REFERENCES}

Richards, M. B. (1949). Brit. F. Nutrit. 3, 132. 